\title{
The risk of bleeding complications on percutaneous biliary drainage in patients with abnormal hemostasis
}

\author{
(ㄴ)Hasan Gündoğdu \\ Recep Tayyip Erdoğan University, Faculty of Medicine, Department of Radiology, Rize, Turkey
}

Cite this article as: Gündoğdu H. The risk of bleeding complications on percutaneous biliary drainage in patients with abnormal hemostasis. Anatolian Curr Med J 2022; 4(1); 103-107.

\begin{abstract}
Aim: To determine whether the risk of bleeding complications in percutaneous biliary drainage is higher in adults whose hemostasis cannot be corrected before the procedure than in those whose hemostasis is corrected.

Material and Method: 62 patients who underwent percutaneous biliary drainage were included in the study. Patients with abnormal hemostasis were divided into those with corrected hemostasis (group I) and uncorrected hemostasis (group II). The groups were evaluated for the presence of bleeding complications by ultrasonography, computed tomography and laboratory findings. The groups were compared in terms of age, gender, side, drainage type, and bleeding complications.

Results: Of the 62 patients included in the study, $52 \%(\mathrm{n}: 32)$ were female and $48 \%(\mathrm{n}: 30)$ were male, with a mean age of 67.6 \pm 9.6 (48-90). Age and female sex ratio were higher in Group II, which was statistically significant ( $<<0.001, p: 0.014)$. There was no statistically significant difference between the groups in terms of side. Internal drainage was applied to patients in group II at a higher rate than group I. There was a statistically significant difference between the groups in terms of drainage type (p:0.002). There were bleeding complications in $19.3 \%(\mathrm{n}: 12)$ of the patients. Bleeding rate was higher in group II $(31.8 \%)$ compared to group I (12.5\%), and there was no statistically significant difference between the groups (p:0.094). None of the patients required surgical treatment due to bleeding and mortality did not occur.

Conclusion: In patients with abnormal hemostasis requiring percutaneous biliary drainage, the rate of bleeding complications was higher in patients whose hemostasis was not corrected than in those with corrected hemostasis.
\end{abstract}

Keywords: Percutaneous biliary drainage, hemobilia, bleeding complications, hemostasis

\section{INTRODUCTION}

Primary or palliative treatment of many biliary diseases demonstrated by cholangiography can be effectively performed with percutaneous biliary drainage (PBD) (1).

PBD can be performed due to benign obstructions such as cholelithiasis, congenital stenosis, cystic dilatations, surgical lesions of the biliary tract, acute cholangitis, or malignant obstructions such as cholangiocellular cancer, pancreatic cancer, gastric cancer. However, most of the patients have malignant disease $(2,3)$.

$\mathrm{PBD}$ is a therapeutic procedure that includes imagingguided wire and catheter manipulation after percutaneous puncture with a right or left-sided approach. The procedure is completed by placing a drainage catheter or stent (1).

PBD is evaluated in the literature in the group of procedures with a serious bleeding risk and difficult to detect or control (4).
Bleeding has been defined as one of several complications reported in the literature. The rate of bleeding complications can vary between 3\% and $26 \%(5,2)$. Bleeding may be asymptomatic or may be seen as major bleeding that causes morbidity and/or mortality. Bleeding may occur as hematomas, hemobilia, hemoperitoneum, arteriovenous fistulas, bilioportal fistulas, and hemothorax (6-8).

Patients with biliary obstruction often have coagulation disorders and therefore an increased risk of bleeding. Hemostasis parameters should be followed in these patients (9).

Coagulopathy is a relative contraindication for PBD (1). In patients with abnormal hemostasis, the bleeding risk of the procedure, the urgency of the procedure, the type and severity of the hemostatic abnormality determine the appropriate management. According to these 
variables, there may be more than one option to correct the coagulation defect. Before the procedure, hemostasis can be corrected or improved with platelet suspension, fresh frozen plasma (ffp), and/or vitamin K (10).

However, in patients with persistent abnormal hemostasis, PBD may still be indicated if it is associated with a lower expected morbidity rate than alternative diagnostic or treatment modalities $(1,4)$.

In studies on the risk of bleeding complications after PBD, patients with normal hemostasis were generally evaluated (11-13). A limited number of studies have compared those with corrected abnormal hemostasis with those with normal hemostasis (14). However, although there are comparative studies on patients whose hemostasis cannot be corrected in some image-guided procedures, there is no study on PBD (15-17).

The aim of this study is to compare adult patients whose hemostasis can be corrected before PBD with medical treatment (ffp, vitamin $\mathrm{K}$, platelet transfusion) and patients who cannot be corrected in terms of bleeding complications.

\section{MATERIAL AND METHOD}

The study was approved by the Non-interventional Clinical Research Ethics Committee of Recep Tayyip Erdoğan University Faculty of Medicine (Date: 23.12.2021, Decision no: 2021/216). All procedures were carried out in accordance with ethical rules and the principles of the Declaration of Helsinki.

Patients over 18 years of age with abnormal hemostasis undergoing $\mathrm{PBD}$ for any possible indication were included in the study. Patients without abnormal hemostasis and patients with abnormal hemostasis who underwent bilateral (right and left) PBD were not included in the study.

Before the procedure, the patients were evaluated for surgical risk, routine tests (blood count, blood glucose, uremia, coagulogram) and pre-anesthesia. Platelet transfusion, fresh frozen plasma and/or vitamin $\mathrm{K}$ were administered to all patients due to inappropriate hemostasis. The patients were processed after signing informed consent.

\section{Technique}

The choice of right or left side before the procedure was decided according to the patient's magnetic resonance, computed tomography, ultrasonography findings and the experience of the operator.

After entering the bile duct with a $21 \mathrm{G}$ Chiba needle under ultrasound and fluoroscopy guidance, a bile sample was taken for culture. 0.018 guide wire was passed through the needle. After insertion of the introducer (AccuStick, Boston Scientific) over the guidewire, cholangiography was obtained. In patients with stenosis, stenosis was passed with a $4 \mathrm{Fr}$ angiographic catheter and 0.035 hydrophilic wire. Then, a multi-purpose $8 \mathrm{Fr}$ biliary drainage catheter was placed over a 0.038 stiff guide wire, and the procedure was terminated by fixing the catheter to the skin.

The presence of bleeding complications in the intraoperative and postoperative period was evaluated with vital signs, laboratory findings, ultrasonography or computed tomography. The patients were followed up until discharge (min-max: 2-20 days).

The patients whose hemodynamic stability did not deteriorate were followed up conservatively. Patients with worsening were first switched to a higher caliber catheter. Despite this, arteriographic embolization was planned for the patients who did not improve. Laparoscopy or laparotomy was considered in patients whose stability could not be achieved despite embolization.

According to the SIR guideline (1), the patients were divided into two groups as corrected hemostasis (group I; platelet count $>50,000$, INR $<1.5$ ) and uncorrected (group II; platelet count $<50,000$, INR $>1.5$ ). Age, gender, reason for drainage, side, type of drainage (external or internal) and presence of bleeding were recorded. The two groups were compared in terms of bleeding risk.

\section{Statistical Analysis}

Data were entered into a database (Microsoft Excel 2010) and analyzed using the SPSS version 20 program (SPSS, Chicago, IL, USA). Frequency distribution and/ or percentages were created for all variables according to total cases. For ordinal scale or higher measures, the number of cases, minimum value, maximum value, arithmetic mean, typical deviation, and standard error were defined. Categorical data of both groups were given as frequencies and percentages (n, \%) within the groups. Student Test, Mann Whitney-U and Chi-square tests were used as significance tests. The limit of significance was accepted as $\mathrm{p}<0.05$.

\section{RESULTS}

Of the 62 patients included in the study, 52\% (n:32) were female and $48 \%$ (n:30) were male, with a mean age of $67.6 \pm 9.6(48-90)$.

A statistically significant difference was found between groups I and II in terms of gender, and the rate of female gender was higher in group II (p:0.014) (Table 1).

The mean age of the patients in group I was 64.5 \pm 9.4 , in group II $73.3 \pm 6.9$ years, and the patients in group II were statistically significantly older $(\mathrm{p}<0.001)$. 
FFP was given to $95 \%$ (n:59) of the patients, vitamin $\mathrm{K}$ was given to $56 \%(\mathrm{n}: 35)$ and platelet transfusion was given to $16 \%$ (n:10). While no statistically significant difference was found between Group I and II in terms of FFP and platelet transfusion administration, statistically significantly more vitamin $\mathrm{K}$ was administered to the patients in group II (Table $\mathbf{1}$ ).

\begin{tabular}{|c|c|c|c|c|c|}
\hline & \multicolumn{2}{|c|}{ Group 1} & \multicolumn{2}{|c|}{ Group 2} & \multirow{2}{*}{ p value } \\
\hline & $\mathbf{N}$ & $\%$ & $\mathbf{N}$ & $\%$ & \\
\hline Sex & & & & & 0.014 \\
\hline Female & 16 & $50 \%$ & 16 & $50 \%$ & \\
\hline Male & 24 & $80 \%$ & 6 & $20 \%$ & \\
\hline Side & & & & & 0.677 \\
\hline Left & 24 & $66.7 \%$ & 12 & $33.3 \%$ & \\
\hline Right & 16 & $61.5 \%$ & 10 & $38.5 \%$ & \\
\hline Fresh froze & & & & & 0.546 \\
\hline No & 3 & $100 \%$ & 0 & $0 \%$ & \\
\hline Yes & 37 & $62.7 \%$ & 22 & $37.3 \%$ & \\
\hline Vitamin K & & & & & 0.003 \\
\hline No & 23 & $85.2 \%$ & 4 & $14.8 \%$ & \\
\hline Yes & 17 & $48.6 \%$ & 18 & $51.4 \%$ & \\
\hline Platelet tra & & & & & 0.733 \\
\hline No & 34 & $65.4 \%$ & 18 & $34.6 \%$ & \\
\hline Yes & 6 & $60 \%$ & 4 & $40 \%$ & \\
\hline Bleeding $\mathrm{cc}$ & ion & & & & 0.094 \\
\hline No & 35 & $70 \%$ & 15 & $30 \%$ & \\
\hline Yes & 5 & $41.7 \%$ & 7 & $58.3 \%$ & \\
\hline Drainage $t$ & & & & & 0.002 \\
\hline Internal & 29 & $80.6 \%$ & 7 & $19.4 \%$ & \\
\hline External & 11 & $42.3 \%$ & 15 & $57.7 \%$ & \\
\hline
\end{tabular}

PBD was applied to $22.6 \%$ (n:14) of the patients for pancreatic cancer, $17.7 \%$ (n: 11 ) for gastric cancer, $11.3 \%$ (n: 7 ) for cholangiocellular cancer (Table 2).

\begin{tabular}{|lcc|}
\hline \multicolumn{3}{l}{ Table 2. Percutaneous biliary drainage indications } \\
\hline & n & \% \\
\hline Pancreas cancer & 14 & 22.6 \\
Gastric cancer & 11 & 17.7 \\
Colon cancer & 8 & 12.9 \\
Cholangiocellular ca & 7 & 11.3 \\
Lymphoma & 4 & 6.5 \\
Rectum cancer & 4 & 6.5 \\
Breast cancer & 2 & 1.6 \\
Choledocholithiasis & 2 & 6.5 \\
Lung cancer & 2 & 6.5 \\
Hepaticojejunostomy stenosis & 2 & 3.2 \\
Ampulla tumor & 1 & 1.6 \\
Primary sclerozan cholangitis & 1 & 1.6 \\
Unknown & 4 & 6.5 \\
Total & 62 & 100.0 \\
\hline
\end{tabular}

While the mean INR value was $1.62 \pm 0.1$ in group II, it was $1.25 \pm 0.7$ in group I. In addition, the median INR value was $1.56(1.22-1.76)$ in patients with bleeding and
1.28 (1.09-1.98) in patients without bleeding, and there was a statistical difference between them (p:0.005).

PBD was applied to $41.9 \%$ (n:26) of the patients from the right side and $58.1 \%(\mathrm{n}: 36)$ of them from the left side. There was no significant difference between groups I and II in terms of sides (p:0.677). There was no difference between the right and left sides in terms of bleeding complications (Table 3).

\begin{tabular}{|lccr|}
\hline \multicolumn{4}{|l}{ Table 3. Comparison of puncture side and bleeding complication } \\
\hline Bleeding complication & Right & Left & \\
\hline Yes & $5(19.2 \%)$ & $7(19.4 \%)$ & p:0.983 \\
No & $21(80.8 \%)$ & $29(80.6 \%)$ & p:0.983 \\
\hline
\end{tabular}

External drainage was applied to $41.9 \%$ (n:26) of the patients and internal drainage was applied to $58.1 \%$ $(n: 36)$ patients. Internal drainage was performed at a higher rate in group I than in group II. There was a statistically significant difference between the groups in terms of drainage type (p:0.002).

Although bleeding complication was proportionally higher in those who had external drainage, no statistically significant difference was found ( $\mathrm{p}: 0,200)$.

There was bleeding complication in $19.3 \%$ (n:12) of the patients, and bleeding was detected in $12.5 \%$ ( $\mathrm{n}: 5)$ of the patients in group I and $31.8 \%$ (n:7) in group II. The bleeding rate was higher in group II compared to group I, and there was no statistically significant difference between the groups (p:0.094).

Hemobilia was present in 9 patients with bleeding. We detected 3 patients with hematoma on ultrasound and all were asymptomatic. In 2 patients, improvement was achieved by replacing the bleeding with a higher caliber (10 or 12 french) catheter to control bleeding. No additional arterial embolization or surgical treatment was required in patients with bleeding.

No procedure-related mortality occurred in any of the patients in the intraoperative and/or perioperative period.

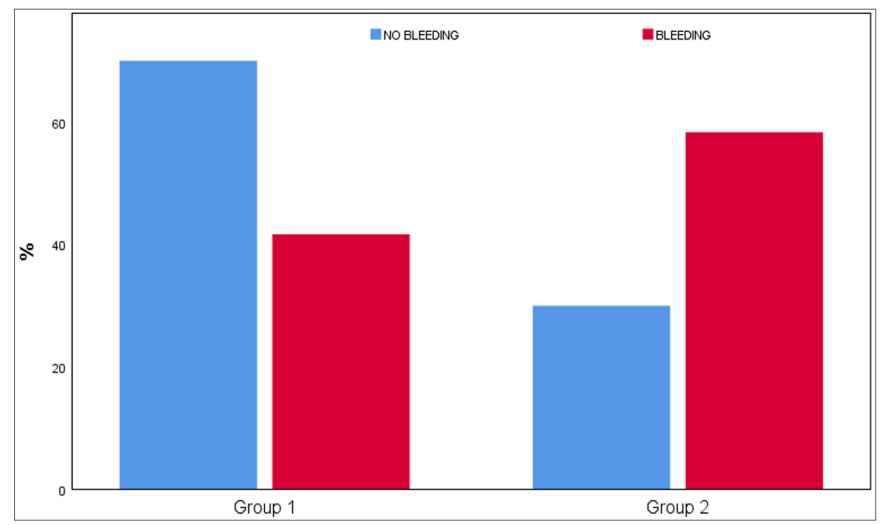

Figure 1. Distribution of patients in groups I and II in terms of bleeding complication 


\section{DISCUSSION}

PBD is a safe and widely practiced interventional radiology procedure for biliary obstructions $(14,18)$.

Bleeding is one of the important complications (5). In the literature, the incidence is in a wide range, from $3 \%$ to $26 \%$, since some authors have defined bleeding complications only when they are symptomatic or cause a decrease in hemoglobin levels, while some authors describe it even if it is asymptomatic $(1,19)$.

Patients undergoing percutaneous intervention often have abnormal hemostasis due to existing disease or pharmacotherapy (10).

In thrombocytopenic patients undergoing percutaneous interventions, the SIR consensus guidelines for hemostasis in a given procedure recommend platelet transfusion for all patients with a platelet count of less than $50,000 / \mathrm{mL}(20,21)$. In addition, the SIR consensus guidelines recommend correcting the INR based on the risk of procedural bleeding. The recommended correction threshold for the INR value for intermediate and high-risk procedures is above 1.5 (22).

In patients with a high INR value, this value can be corrected with various therapeutic options (9). However, in some patients, this value cannot be made suitable for the procedure. In these patients, if the benefit of the procedure is higher than the alternative diagnosis or treatment methods and the expected morbidity rate is low, PBD can still be applied $(1,4)$.

There is also a relative lack of evidence of acceptable INRs for image-guided procedures. Some studies have found little association between abnormal hemostasis and hemorrhagic complications $(16,17,23)$.

Studies on PBD have generally evaluated bleeding complications in patients with normal hemostasis, and studies on patients with abnormal hemostasis are limited $(5,7,9,13,14)$. To the best of our knowledge, our study is the first study to group and evaluate patients with abnormal hemostasis.

In the study in which patients with abnormal hemostasis were included; Vital, laboratory and radiological followups were performed. All asymptomatic or symptomatic bleeding complications were recorded.

Nenstiel et al. (19) reported the rate of bleeding complications as $13 \%$ in their study in patients with normal hemostasis, and as $15.8 \%$ in the study of Hougton et al. (14) including patients with abnormal hemostasis with corrected hemostasis. In our study, this rate was $19.3 \%$, and we think that this is related to the patient population. L'Hermine et al. (13) reported that $6 \%$ of bleedings were severe, and $2-8 \%$ of them were caused by arterial lesions. We did not detect arterial bleeding in our study.

In our study, the rate of bleeding in patients whose abnormal hemostasis could not be corrected was higher than those whose hemostasis was corrected. Hougtan et al. reported a lower rate of bleeding complications in patients with corrected hemostasis than those with normal hemostasis, and did not analyze correction of hemostasis as a possible risk factor (14). This difference is due to the small number of patients whose hemostasis was corrected in the study of Hougtan et al.

Choi et al. (5) in a retrospective study in which they analyzed the risk factors for the development of bleeding complications in the $\mathrm{PBD}$ procedure; reported that platelet count of $50000 / \mathrm{mm} 3$ or less and INR of 1.5 or more were risk factors, but it was not statistically significant in multivariate analysis. Similarly, in our study, the percentage of bleeding in patients with an INR value above 1.5 was higher than in patients with an INR value below it, but it was not statistically significant.

Rivera-Sanfeliz et al. (7) reported that there was proportionally more bleeding in the left approach. Choi et al. (5) stated that left-access PBD was the only independent risk factor for arterial damage. Hougtan et al.(9) in their study comparing the right and left approaches; reported that the bleeding rate was low in the left approach. In this study, bleeding rates were similar in the right and left approaches.

In the study of Hougtan et al. including patients with corrected hemostasis, they found more patients with corrected hemostasis in the left approach and reported that this may be a factor reducing the risk in the left approach group (14). Similarly, in our study, a proportionally more left-sided approach was used in the group whose hemostasis was corrected. We think that this point needs analysis with studies conducted with more patients.

Rivera-Sanfeliz et al. (7) reported that there was no relationship between drainage type and bleeding, while Hougtan et al. (14) reported that there was proportionally more bleeding in those who had external drainage. We found proportionally more bleeding in patients who underwent external drainage, similar to Hougtan et al.

PBD indications are generally of malignant origin, and in the study of Uberoi et al. (3) the most common cause was pancreatic cancer, and Choi et al. (5) defined cholangiocellular carcinoma. The most common cause in this study was pancreatic cancer.

The main limitations of our study are that it was singlecentered, the number of patients was small, and abnormal hemostasis parameters were not evaluated separately. 


\section{CONCLUSION}

In patients with abnormal hemostasis requiring percutaneous biliary drainage, bleeding complications were more common in patients with uncorrected hemostasis than in those with corrected hemostasis, but did not reach statistical significance. Also, bleedingrelated mortality did not occur.

\section{ETHICAL DECLARATION}

Ethics Committee Approval: The study was approved by the Non-interventional Clinical Research Ethics Committee of Recep Tayyip Erdogan University Faculty of Medicine (Date: 23.12.2021, Decision no: 2021/216).

Informed Consent: All patients signed the free and informed consent form.

Referee Evaluation Process: Externally peer-reviewed.

Conflict of Interest Statement: The authors have no conflicts of interest to declare.

Financial Disclosure: The authors declared that this study has received no financial support.

Author Contributions: All of the authors declare that they have all participated in the design, execution, and analysis of the paper, and that they have approved the final version.

\section{REFERENCES}

1. Saad WE, Wallace MJ, Wojak JC, Kundu S, Cardella JF Quality improvement guidelines for percutaneous transhepatic cholangiography, biliary drainage, and percutaneous cholecystostomy. J Vasc Interv Radiol 2010; 21: 789-95.

2. Kühn JP, Busemann A, Lerch MM, et al. Percutaneous biliary drainage in patients with nondilated intrahepatic bile ducts compared with patients with dilated intrahepatic bile ducts. AJR Am J Roentgenol 2010; 195: 851-7.

3. Uberoi R, Das N, Moss J, Robertson I. British Society of Interventional Radiology: Biliary Drainage and Stenting Registry (BDSR). Cardiovasc Intervent Radiol 2012; 35: 127-38.

4. Patel, IJ, Davidson JC, Nikolic B, et al. consensus guidelines for periprocedural management of coagulation status and hemostasis risk in percutaneous image-guided interventions. J Vasc Intervent Radiol 2012; 23: 727 -36.

5. Choi SH, Gwon DI, Ko GY, et al. Hepatic arterial injuries in 3110 patients following percutaneous transhepatic biliary drainage. Radiology 2011; 261: 969-75.

6. Tapping CR, Byass OR, Cast JE. Percutaneous transhepatic biliary drainage (PTBD) with or without stenting-complications, restent rate and a new risk stratification score. Eur Radiol 2011; 21: $1948-55$

7. Rivera-Sanfeliz GM, Assar OS, LaBerge JM, et al. Incidence of important hemobilia following transhepatic biliary drainage left sided versus right sided approaches. Cardiovasc Intervent Radiol 2004; 27: 137-9.

8. Özdemir A, Şahan MH. Ultrasonografi rehberliğinde perkütan kesici karaciğer biyopsisi (parankim ve lezyon): klinik deneyimimiz. Kırıkkale Üniversitesi Tip Fakültesi Derg 2019; 21: 325-31.
9. Houghton EJ, Zeledón M, Acquafresca P, Finger C, Palermo M, Giménez ME. Prospective comparison of bleeding complications between right and left approaches in percutaneous biliary drainage. Surg Laparosc Endosc Percutan Tech 2019; 29: 7-12.

10. Wiltrout C, Kondo K. Correction of coagulopathy for percutaneous interventions. Semin Intervent Radiol 2010; 27: $338-47$.

11. Donkol RH, Latif NA, Moghazy K. Percutaneous imagingguided interventions for acute biliary disorders in high surgical risk patients. World J Radiol 2010; 28: 358-67.

12. Garcarek J, Kurcz J, Guziński M, et al. Ten years single center experience in percutaneous transhepatic decompression of biliary tree in patients with malignant obstructive jaundice. Adv Clin Exp Med 2012; 2: 621-32.

13. L'Hermine C, Ernst O, Delemazure O, et al. Arterial complications of percutaneous transhepatic biliary drainage. Cardiovasc Intervent Radiol 1996; 19: 160-4.

14. Houghton EJ, Invernizzi E, Acquafresca P, Palermo M, Giménez ME. Risk of bleeding complications in percutaneous biliary drainage: the paradox of the normal hemostasis. Arq Bras Cir Dig 2019; 21:e1454.

15. Navin PJ, White ML, Nichols FC, et al. Periprocedural major bleeding risk of image-guided percutaneous chest tube placement in patients with an elevated international normalized ratio. J Vasc Interv Radiol 2019; 30: 1765-8.

16. Martin JH, Rosser CJ, Linebach RF, McCullough DL, Assimos DG. Are coagulation studies necessary before percutaneous nephrostomy? Tech Urol 2000; 6: 205-7.

17. Fisher NC, Mutimer DJ. Central venous cannulation in patients with liver disease and coagulopathy - a prospective audit. Intens Care Med 1999; 25: 481-5.

18. Quencer K, Tadros A, Marashi K, et al. Bleeding after percutaneous transhepatic biliary drainage: incidence, causes and treatments. J Clin Med 2018; 7: 94

19. Nennstiel S, Weber A, Frick G, et al. Drainage-related complications in percutaneous transhepatic biliary drainage an analysis over 10 years. J Clin Gastroenterol 2015; 49: 764-70.

20. Haas B, Trerotola S, Itkin M, et al. Tunneled central venous catheter insertion in patients with coagulopathy and thrombocytopenia. J Vasc Interv Radiol 2009; 20: 35-6.

21. Haas B, Chittams JL, Trerotola SO. Large-bore tunneled central venous catheter insertion in patients with coagulopathy. J Vasc Interv Radiol 2010; 21: 212-7.

22. Malloy PC, Grassi CJ, Kundu S, et al. Consensus guidelines for periprocedural management of coagulation status and hemostasis risk in percutaneous image-guided interventions. J Vasc Interv Radiol 2009;20: 240-9.

23. Stecker MS, Johnson MS, Ying J, et al. Time to hemostasis after traction removal of tunneled cuffed central venous catheters. J Vasc Interv Radiol 2007; 18: 1232-9. 